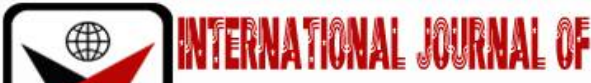

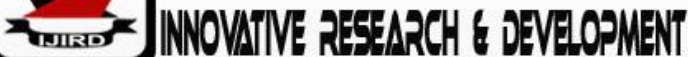

ISSN 2278 - 0211 (Online)

\section{A Review into the Clinical Characteristics of 2019-nCoV and Its Potential Impact on African Economy}

\begin{tabular}{c} 
Dada, Abiodun \\
Lecturer, Department of Environmental and Occupational Health, \\
College of Health Sciences and Technology, Ijero Ekiti, Nigeria \\
Fasoro, Olatunji \\
Chief Lecturer, Department of Pharmacy, \\
College of Health Sciences and Technology, Ijero Ekiti, Nigeria \\
Olusuyi, Abimbola \\
Principal Instructor, Department of Community Health, \\
College of Health Sciences and Technology, Ijero Ekiti, Nigeria \\
Adewumi, Michael \\
Senior Lecturer, Department of Environmental and Occupational Health, \\
College of Health Sciences and Technology, Ijero Ekiti, Nigeria \\
Odeyemi, Taye \\
Senior Instructor, Department of Environmental and Occupational Health, \\
College of Health Sciences and Technology, Ijero Ekiti, Nigeria \\
Ogunyemi, Kayode \\
Principal Instructor, Department of Environmental and Occupational Health, \\
College of Health Sciences and Technology, Ijero Ekiti, Nigeria \\
Oluwatuyi, Victor \\
Lecturer, Department of Community Health, \\
College of Health Sciences and Technology, Ijero Ekiti, Nigeria \\
\hline
\end{tabular}

\section{Abstract:}

Introduction: The new coronavirus (2019-nCoV) or (SARS-CoV-2) was first observed in China in early December and by the end of January 2020, it had spread across 171 countries which was gradually affecting the global economy. The surge of COVID 19 in African countries has the potential to take more lives, disintegrate economies, pressured the health systems, and trigger lasting geological and social change if it's not properly managed. This review summarizes the clinical characteristics of the new COVID 19 and the potential impact on African economy

Method: The methodology adopted was purely on content analysis of secondary data and observed information from health survey and economic reports from Africa through a comprehensive search using electronic and non-electronic databases. A literature search from the databases of Africa Center for Disease Control and Prevention (ACDC), World Health Organization (WHO) database and Center for Strategic and International Studies (CSIS) were conducted.

Results: Our review of the subject matter indicated that many areas of African economy and Public Health system appear to be directly vulnerable to the impacts of the novel COVID-19 such as some key financial sectors, manufacturing and transportation, energy and mining, trade and tourism, Pharmaceutical and health system as a result of inadequate drug trials, unsuccessful vaccine trials, travel ban, mobility restrictions and limitation in surveillance/testing.

Conclusion: Thesurge of this virus has disrupted the medical and public health,economic and infrastructure of most countries in African. Hence, African countries should come together and develop holistic approach to tackle the surge. Individual countries needs to improve their health care system, strengthening their laboratory and institutional capacity so that they can carry out clinical trials of new drugs in emergency period. Action framework should be designed with assistance from private sectors in order to secure food supply system, provide stimulus packages and support vulnerable populations during health crisis.

Keywords: Clinical, Impact, Economy

\section{Introduction}

Viral diseases continue to appear and present a serious threat to mankind. In the last two decades, several viral outbreaks for example: the severe acute respiratory syndrome coronavirus (SARS-CoV) which occur in 2003 and H1N1 influenza virus in 2009 have emerged. Then in 2012, the Middle East respiratory syndrome coronavirus (MERS-CoV) was first spotted in Saudi Arabia [1]. 
However, in early December, 2019, a handful of patients showing signs of respiratory diseases of unknown sources in Wuhan and Hubei regions were reported to the Ministry of Health in China. Almost all these emerging cases were investigated and connected to a community fish depot and commercial market [4]. The microbial agent behind this bunch of respiratory illness was later recognized as the novel coronavirus 2019. At the onset of the 2019-nCoV upsurge in China, there was no familiar information about the disease, apart from the fact that transmission by direct exposure occurred at the communal fish depot and market. [4].

On 30thJanuary, 2020, the eruption of the disease was announced a Public Health Emergency of International Concern (PHEIC) by the World Health Organization as it had appeared in over 19 countries with six countries reporting person-to-person transmission. In early February, 2020, the Director-General of WHO, Dr. Tedros Ghebreyesus, publicly announced the new name of the disease as "COVID-19," meaning "coronavirus disease 2019"[3].

Both Egypt and Algeria confirmed their first cases on Feb 14 and Feb 25, 2020 respectively. Various approaches have been put in place to obviate and halt importation of cases to countries in Africa [3], however, the tendency to counter and arrest the transmission locally after importation depends on the adoption of strict measures to identify the cases, curtailing the spread and general management. These approaches includes but not limited to keen monitoring and speedy detection of suspected cases, patient isolation in standard isolation centers, and contact tracing. [6] The use of such scientific and comprehensive solutions and interventions depends on each country's public health system, laboratory facilities, infrastructures and resources.

Africa and its Sub-Saharan countries are speeding toward a political crisis as well as a health and economic catastrophe in the face of the rapidly expanding COVID-19 pandemic. As of March 18, 2020, there are 25 sub-Saharan African countries with confirmed cases. And every day brings new reports of infections, even in landlocked countries such as the Central African Republic and small countries with tiny populations such as Equatorial Guinea and the Seychelles.[18]

Nigeria, South Africa, Kenya, Ghana and Mozambique, among other countries had taken series of proactive measures to reduce and prevent the spread of COVID-19 pandemic. Various sporting events had been cancelled, Institutions, sacred spaces for worship and open markets are closed, Sub-Saharan Africans, like people across the world, are wracked with concern about the implications for their well-being and their livelihoods.[18, 19]

There remain considerable knowledge gaps on 2019-nCoV, most especially on the clinical presentation, the impact on African economic development and how to survive this Public health crisis. Herein, we present a review of the literature with the aim of bridging the knowledge gap since knowledge about this virus is developing rapidly.

\begin{tabular}{|c|c|c|c|c|c|c|}
\hline $\begin{array}{l}\text { African } \\
\text { Region }\end{array}$ & $\begin{array}{c}\text { Total } \\
\text { Confirmed } \\
\text { Cases }\end{array}$ & $\begin{array}{c}\text { Total } \\
\text { Confirmed } \\
\text { New Cases }\end{array}$ & $\begin{array}{c}\text { Total } \\
\text { Deaths }\end{array}$ & $\begin{array}{l}\text { Total new } \\
\text { Deaths }\end{array}$ & $\begin{array}{l}\text { Transmission } \\
\text { Classification }\end{array}$ & $\begin{array}{l}\text { Days Since Last } \\
\text { Reported Case }\end{array}$ \\
\hline Algeria & 20 & 0 & 0 & 0 & Local Transmission & 2 \\
\hline $\begin{array}{l}\text { South } \\
\text { Africa }\end{array}$ & 7 & 0 & 0 & 0 & Imported Cases Only & 1 \\
\hline Senegal & 4 & 0 & 0 & 0 & Imported Cases Only & 6 \\
\hline $\begin{array}{c}\text { Burkina } \\
\text { Faso }\end{array}$ & 2 & 2 & 0 & 0 & Imported Cases Only & 0 \\
\hline Cameroon & 2 & 0 & 0 & 0 & Local Transmission & 4 \\
\hline Nigeria & 2 & 0 & 0 & 0 & $\begin{array}{l}\text { Imported } \\
\text { Cases Only }\end{array}$ & 2 \\
\hline $\begin{array}{c}\text { Democrati } \\
\text { c Republic } \\
\text { of the } \\
\text { Congo }\end{array}$ & 1 & 1 & 0 & 0 & Imported Cases Only & 0 \\
\hline Source[3] & & & & & & \\
\hline
\end{tabular}

Table 1: Countries or Territories in Africa with Laboratory-Confirmed COVID-19

Cases and Deaths, Data as of 11 March 2020

\section{Methodology}

The methodology adopted was purely on content analysis of secondary data and observed information from Health survey through a comprehensive search by using electronic and non-electronic databases. Reports and presentations from African Center for Disease Control (ACDC), African Health Forum (AFR) were used for review. A literature search was performed using the PubMed database, World Health Organization (WHO) research database, Center for strategic and International studies (CSIS) and World Economic Forum (WEF). Related published literatures and 
documents were also searched in a systematic way using a range of key words relating to the impact of COVID 19 on the economy, Clinical manifestation and the available therapeutic measures

\subsection{History of Corona Virus}

Coronavirus is a family of coronaviridae, the outer structure when viewed under electron microscope present spike-like projection making it to appear in a crown shape, hence the name corona. The virus is an envelope positive sense containing single stranded RNA nucleic materials, ranging from $24-31 \mathrm{kbs}$ in length. The subdivision of the family of coronaviruses namely HKU1, NL63, 229E and OC43 have been known to cause mild injury to the lungs and respiratory distress syndrome in human which may leads to pulmonary failure or result into death [6].

The world had witnessed two series of events relating to coronavirus; between 2002-2003, in Guangdong province, China, a new coronavirus of $\beta$ genera emerged, it was designated as a severe acute respiratory syndrome (SARS-CoV) with 8422 active cases, causing the death of 916 people. 10 years later, another viral agent belonging to coronavirus family, also of bat origin, known as Middle East Respiratory Syndrome (MERS-CoV) caused an endemic especially in Saudi Arabia and other countries in the Middle East, with 2494 people affected and 858 recorded deaths [5].

\subsection{Origin and Spread of $2019-n \mathrm{CoV}$}

In early December, 2019, several bunch of cases with respiratory diseases of unknown origin in Wuhan and Hubei regions in China were reported and registered to the local hospitals and Chinese health commission. Nearly all of these cases were investigated and linked to a local fish depot and animal market [4]. The microbial agent responsible for this bunch of respiratory illness was identified as a 2019 novel coronavirus [2]. At the onset of the 2019-nCoV epidemic in China, there was no familiar information about the disease, except that it was transmitted by direct exposure at the local fish depot and commercial market. However, human spread of 2019-nCoV was later established [4, 6]. The monitoring techniques, kept for decades after the SARS outbreak, was initiated again and bodily samples, including blood and respiratory swab of patients were sent to reference laboratories for etiologic examinations. By late December 2019, China officially notified the World Health Organization of the new outbreak of the disease and early January 2020, the Wuhan sea food depot and its commercial market were shutdown. On 7th January the virus was categorized as a coronavirus that had over 95\% RNA resemblance with the bat coronavirus and over 75\% similarity with the SARS- CoV. Food samples taken from the sea food market also tested positive, indicating that the virus emanated from the market. The number of cases started increasing, some of which did not even visit the sea food market, suggestive of the fact that person-to-person transmission was occurring [4]. Cases in other countries that shares border with China were reported in people who were returning from Wuhan. Transmission to healthcare workers caring for patients was also occurring. By 23rd January, over 11 million population of Wuhan was placed under lock down with restrictions of entry and exit from the region.

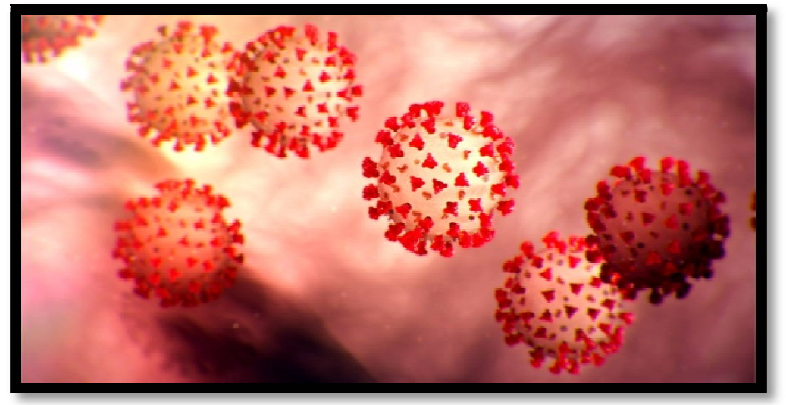

Figure 1: The 2019 Novel Coronavirus (2019-nCoV) (Image: ACDC)

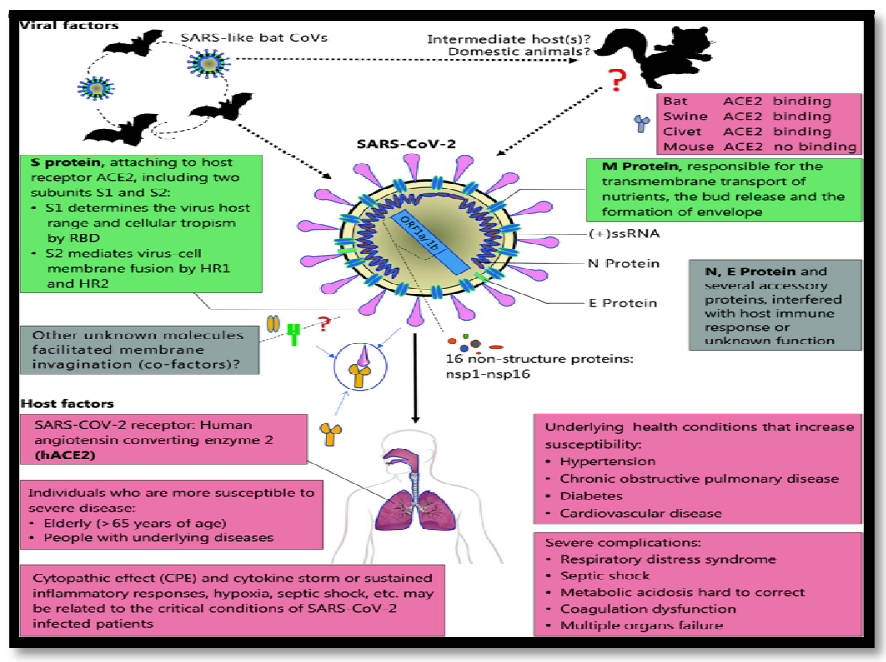

Figure 2: Viral Factors and Host Factors for COID 19 Infections Source [12] 


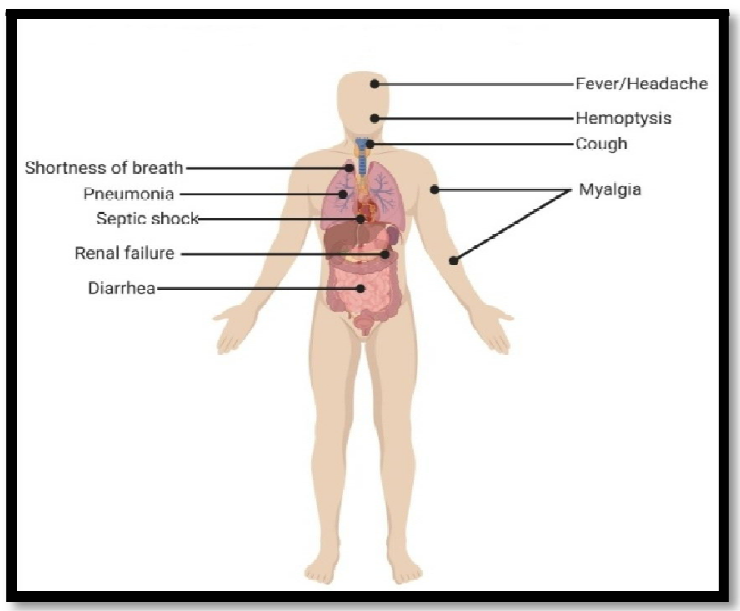

Figure 3: Clinical Presentation of Patient with COVID 19

Source [5]

\subsection{Diagnosis}

A suspect case can be explained as one with fever, sore throat and dry cough who must have travelled to places with higher cases or in contact with confirmed COVID-19 infection patient. However, a confirmed case is usually an individual with a positive molecular test.

Standard diagnosis is by molecular analysis on respiratory samples for example swab from the throat, sputum, broncho alveolar lavageetc). In severe cases, Virus may be detected in the blood.[10].Affordable test kits are also not available, but with the ongoing research, commercial tests may be available soon.

The X-ray examination of the chest (CXR) usually indicates bilateral infiltrates but may be normal at the incipiency or inception of the disease. The CT is more reliable and specific. CT imaging generally shows infiltrates and sub segmental consolidation [8]. It also shows the aberrant conditions of the lungs of patients with no clinical evidence. As a matter of fact, aberrant conditions have been used to diagnose for COVID-19 in asymptomatic patients. Though, on repeating the molecular test, many of the patients turns positive

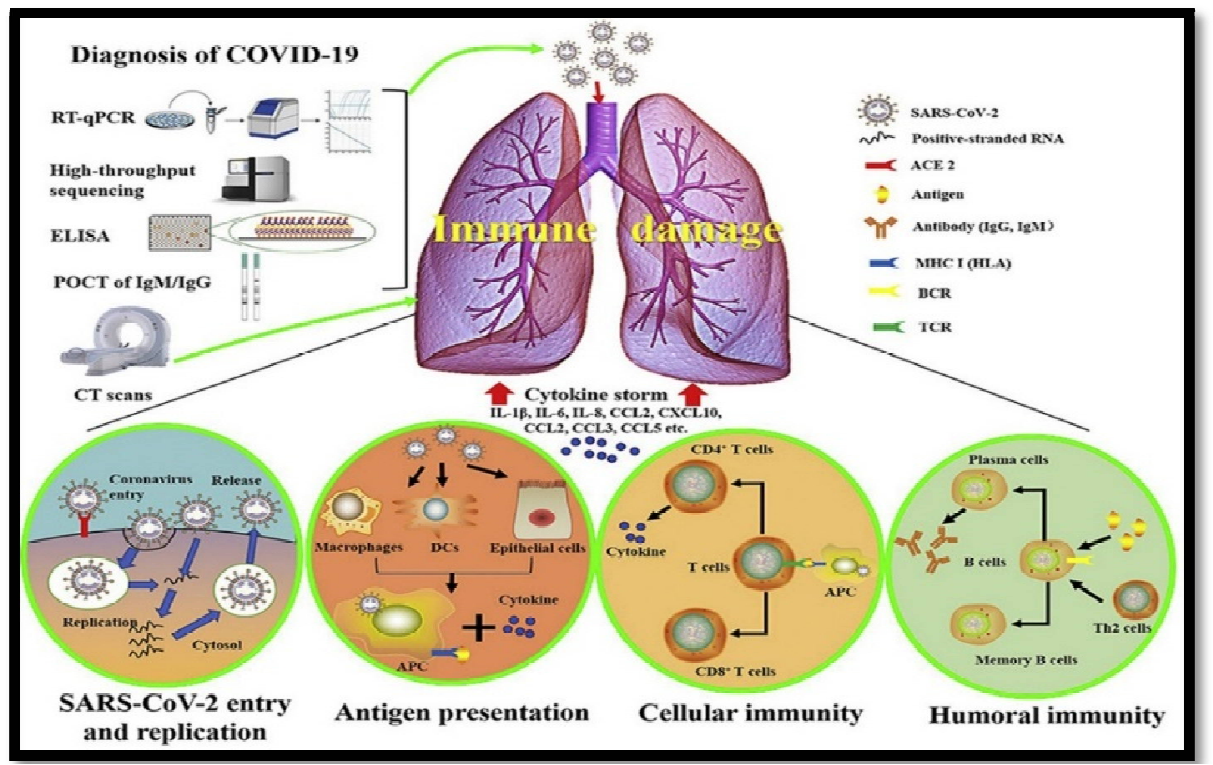

Figure 4: Diagnosis of COVID 19

Source [8]

\subsection{Prevention}

At this time there are no approved treatment modules for this infection, prevention is important. Several properties of this virus make prevention difficult namely, non-specific features of the disease, the infectivity even before onset of symptoms in the incubation period, transmission from asymptomatic people, long incubation period, tropism for mucosal surfaces such as the conjunctiva, prolonged duration of the illness and quick transmission even after clinical recovery[9].

Isolation of confirmed or suspected cases with mild illness at home is recommended. The ventilation at home should be good with sunlight to allow for destruction of virus. Patients should be asked to wear a simple approved mask and practice cough hygiene. Caregivers should be asked to wear a surgical mask when in the same room with patient and use hand hygiene every 15-20 min [10].

In Isolation centers, patients should be placed in separate rooms or cohorted together. The rooms and surfaces and equipment should undergo regular decontamination preferably with sodium hypochlorite. Healthcare workers should be provided with fit tested N95 respirators and protective suits and goggles[10, 16]. Airborne transmission precautions 
should be taken during aerosol generating procedures such as intubation, suction and tracheostomies. All contacts including healthcare workers should be monitored for development of symptoms of COVID-19. Patients can be discharged from isolation once they are afebrile for atleast 3 days and have two consecutive negative molecular tests at 1 day sampling interval.

At the community level, people should be asked to avoid crowded areas and postpone non-essential travel to places with ongoing transmission. They should be asked to practice cough hygiene by coughing in sleeve/ tissue rather than hands and practice hand hygiene frequently every 15-20 min. Patients with respiratory symptoms should be asked to use surgical masks. $[18,20]$.The use of mask by healthy people in public places has now shown to be effective against respiratory viral infections and is currently under investigation by WHO. However, assembly of large number of people found in(entertainment centers, event gardens, parks etc.) should be prohibited, introduction of new legislation to prohibit selling and trading of wild animals should be considered. A candidate vaccine should be developed to prevent future occurrence

\subsection{Treatment}

Treatment is essentially supportive and symptomatic. The first step is to ensure adequate isolation to prevent transmission to other patients and healthcare workers. Mild illness should be managed at home with counseling about danger signs[14]. The usual principles are maintaining hydration and nutrition and controlling fever and cough. In patients showing hypoxia, provision of oxygen through nasal prongs, face mask, or non-invasive ventilation should be used. Mechanical ventilation and even extra corporeal membrane oxygen support may be needed [15]. Antibiotics are required if co-infections are suspected or proven. There is, as of now, no approved treatment for COVID-19. Antiviral drugs such as ribavirin, lopinavir-ritonavir have been used based on the experience with SARS and MERS. In a historical control study in patients with SARS, patients treated with lopinavir-ritonavir with ribavirin had better outcomes as compared to those given ribavirin alone.

Some countries had adopted remdevir as the possible treatment regimen for Covid-19, but there is anecdotal experience with use of remdevir, a broad-spectrum anti RNA drug developed for Ebola in management of COVID-19 [16]. More evidence is needed before this drug is recommended. Other drugs proposed for therapy are arbidol (an antiviral drug available in Russia and China), intravenous immunoglobulin, interferons, chloroquine and plasma of patients recovered from COVID-19.

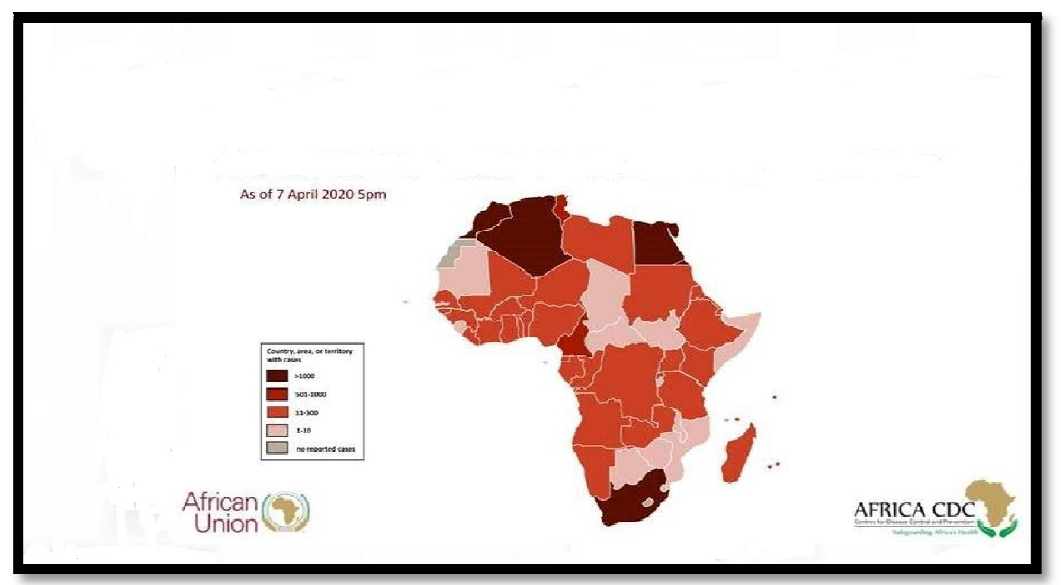

Figure 5: African Union Member States Reporting COVID 19 Cases (As Of 7th, April, 2020)[19] Source [19]

Total number positive cases in Africa 10,252

- 52 countries

- 492 deaths

- 989 recovery cases by Region

- African Union Member States (52) reporting COVID-19 cases (10,252), deaths (492), and recoveries (989) by region:

- $\quad$ Central (950 cases; 33 deaths; 34 recoveries): Burundi (3; 0; 0), Cameroon (650; 9; 17), Central African Republic $(9 ; 0 ; 3)$, Chad $(9 ; 0 ; 1)$, Congo $(49 ; 5 ; 2)$, DRC $(180 ; 18 ; 9)$, Equatorial Guinea $(16 ; 0 ; 1)$, Gabon $(30 ; 1 ; 1)$, Sao Tome \& Principe $(4 ; 0 ; 0)$

- $\quad$ Eastern (922; 18; 54): Djibouti $(121 ; 0 ; 18)$, Eritrea (31; 0; 0), Ethiopia (52; 2; 4), Kenya (172; 6; 7), Madagascar $(88 ; 0 ; 7)$, Mauritius $(244 ; 7 ; 7)$, Rwanda $(105 ; 0 ; 4)$, Seychelles $(11 ; 0 ; 0)$, Somalia $(7 ; 0 ; 1)$, South Sudan (1; 0; 0$)$, Sudan $(14 ; 2 ; 3)$, Tanzania $(24 ; 1 ; 3)$, Uganda $(52 ; 0 ; 0)$

- $\quad$ Northern $(4,506 ; 365 ; 444)$ : Algeria $(1,423 ; 173 ; 90)$, Egypt $(1,322 ; 85 ; 259)$, Libya $(18 ; 1 ; 0)$, Mauritania (6; $1 ; 2)$, Morocco $(1,141 ; 83 ; 88)$, Tunisia $(596 ; 22 ; 5)$

- $\quad$ Southern $(1,864 ; 19 ; 61)$ : Angola $(16 ; 2 ; 2)$, Botswana $(6 ; 1 ; 0)$, Eswatini $(10 ; 0 ; 3)$, Malawi $(8 ; 1 ; 0)$, Mozambique $(10 ; 0 ; 1)$, Namibia $(16 ; 0 ; 3)$, South Africa $(1,749 ; 13 ; 45)$, Zambia $(39 ; 1 ; 7)$, Zimbabwe $(10 ; 1 ; 0)$ 
- Western $(2,010 ; 57 ; 396)$ : Benin $(26 ; 1 ; 5)$, Burkina Faso $(364 ; 18 ; 108)$, Cape Verde $(7 ; 1 ; 1)$, Côte d'Ivoire (323; 3; 41), Gambia (4; 1; 2), Ghana (287; 5; 31), Guinea (128; 0; 5), Guinea-Bissau (18; 0; 2), Liberia (14; 3; 3), Mali (47; $5 ; 9)$, Niger (253; 10; 26), Nigeria (238; 5; 35), Senegal (237; 2; 105), Sierra Leone $(6 ; 0 ; 0)$, Togo (58; 3; 23)

Most impacted African nations per region (as of April 7 2020):

- $\quad$ Southern Africa = South Africa; 1,686 cases, 12 deaths, 95 recoveries

- $\quad$ East Africa = Mauritius; 244 cases, 7 deaths, 7 recoveries

- West Africa = Burkina Faso; 364 cases, 18 deaths, 108 recoveries

- $\quad$ Central Africa = Cameroon; 658 cases, 9 deaths, 17 recoveries

- $\quad$ North Africa = Algeria; 1,423 cases, 173 deaths, 90 recoveries As of April 2; Algeria toppled Egypt to become the most impacted North African country

Then, as of 9 am EAT 14 April 2020, a total of 15,284 COVID-19 cases and 816 (CFR: 5\%) deaths have been reported in 52 African countries. Since the last brief, the number of COVID-19 cases has increased by 52\% (5,198 cases). The five countries in Africa with the highest cumulative number of cases (proportion of reported cases in Africa) are South Africa $(2,272 ; 15 \%)$, Egypt $(2,190 ; 14 \%)$ Algeria (1,914; 13\%), Morocco (1,763; 12\%) and Cameroon (820; 5\%). When population is taken into consideration, Djibouti (30.2), Mauritius(25.5), Seychelles (11.2), Tunisia (6.1), and Morocco (4.8) are reporting the most cases per 100,000 population within the continent. Fifteen countries are reporting case fatality rates higher than the global case fatality rate of $6 \%$. Africa CDC is working with all affected countries and is mobilizing laboratory, surveillance, and other response support where requested. [19]

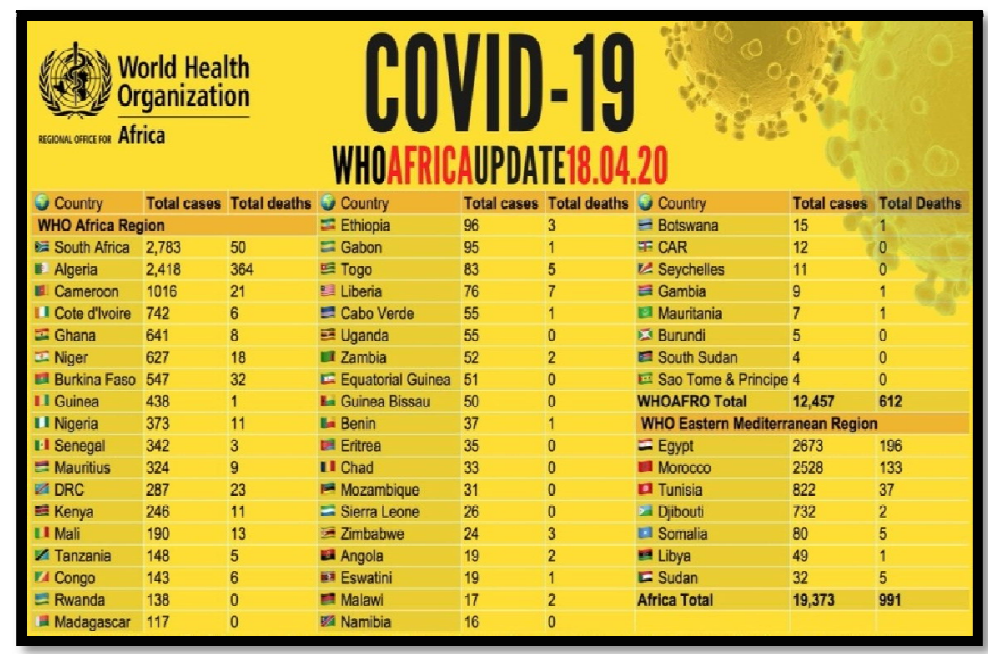

Figure 6: WHO Africa Region COVID 19 Reports As of $18^{\text {th }}$ April, 2020

Source [3]

\section{Impact of 2019- nCoV on African Economy}

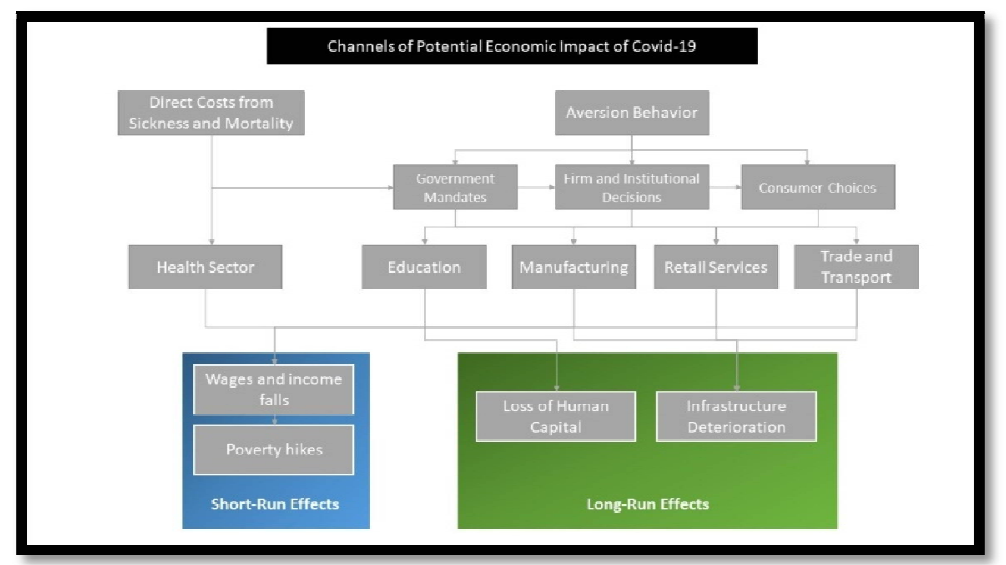

Figure 7: Broad Channels of Short-term Economic Impact of COVID 19 Pandemic Source [17]

\subsection{Impact on key financial Sector $[18,21,24,26]$}

\subsubsection{Merger \& Acquisition Activity}

Most African countries are battling with the spread of the virus in which various mobility restrictions mechanisms are adopted: ranging from enforcement of quarantine, travel ban, curfew to total lockdown, As such, these events could potentially be significant enough to trigger a change to the terms of an M\&A transaction currently in progress, transaction 
deals could be delayed. The pandemic situations could also cause setback to M\&A due sedulity and carefulness, necessary for a transaction to progress to finalization which eventually could result in the termination of the deals. This could hamper investment opportunities and consumers demand in African countries

\subsubsection{Financial Institutions}

The activities and responsibilities of the African financial institutions might be shelved as a result of the skepticism and doubt surrounding the impact of COVID-19, there is decline in the confidence of financial investors and stakeholders. It remains unclear whether the huge global economic downturn caused by decreased output in China will impact on African lenders and compel financial institutions on the continent to be more lenient towards borrowers and cut them some slack.

\subsubsection{Local Markets}

Since commodity prices determines the rate of African economic growth. local prices of have been driven down by the virus's global impact. The uncertainty of the impact of COVID-19 on local markets is expected to lead to increased risk aversion from investors who are waiting to see its potential impact in Africa. On advantage, a partial drop in the prices of share always provides opportunities for smart investors.

\subsubsection{Insurance}

As at when the Covid-19 crisis started in Africa, Businesses, properties and individuals are uninsured for any COVID-19 impacts as losses related to an epidemic or pandemic would usually not be covered in insurance policies, irrespective of whether the insurance covers business interruption, damage to properties, product loss of life and productsor travel insurance. This is because Covid 19 is an emerging disease which has not been captured in any existing insurance contract

\subsection{Impact on Infrastructure}

China is a long standing partner to most African countries on Infrastructural development, especially sub-Saharan Africa in an attempt to manage their natural resources, Belt and Road Initiative (BRI) was created where billions of dollars are loaned out to Africa.

The impact of the virus has already affected the activity around China's loan initiates which will in turns affect Infrastructure developmental support for Africa. As a result of China's dwindling health sector and economic depression for the country, there may be diversion of financial resources away from the supporting initiatives to Africa. They must remain focus if they want to be a major force in African infrastructure development

\subsection{Impact on Trade}

COVID-19 pandemic is speculated to affect China's -Africans trade for a number of months. As China is Africa's largest trading partner, the impact of this pandemic are already being felt in some Africa countries. With China already locked its manufacturing factories and its borders, there has been incessant fallouts in demand for African commodities. Importers and exporters are cancelling their order due to port closure, Retailers of commodities in Africa are being forced to offload products elsewhere at an exorbitant rate or forfeit their goods to governments

Countries like the Kenya, Zambia, Nigeria and Ghana are significantly exposed to risk in terms of exporting their products, such as such as oil, iron, coffee and copper to other countries which in turns impact their economies. In the Manufacturing sectors, the impact of covid 19 will be felt because when factories closed there will be disruptions in supply chain of raw materials and other products to multinational companies with either increased costs or reduced orders

\subsection{Impact on Energy and Mining}

African mining and Energy industry faces an inevitable hit from COVID-19 outbreak, although it is unclear as to how much and for how long the sector will be impacted. Chinas investor controlled about 20 mining operations in Africa. Total closure had led to a decrease in demand for mineral resources like iron ore from other countries. Mining companies that provides lithium, copper and iron ore in Africa have already recorded reduction in demand from their partners in other European countries leading to global supply chain disruptions.

The European countries that import and sell oil and other petroleum products to African countries are diverting their products to other countries abroad due to boarder closures, mobility restrictions and reduction in demands caused by this pandemic. The efficiency and productivity of the workforce in the mining regions in Africa could be significantly altered by the surge of COVID 19, the tendency of skilled technicians and contractors to travel from affected areas and the capacity of labour-intensive mining operations to produce raw materials could be affected.

\subsection{Impact on Industrials, Manufacturing and Transportation}

Due to the effect of this pandemic, it is not clear as to when companies will commence production but once they reopen, both imports and exports will be further delayed by the aftermath congestion and backlog. construction companies is currently affected due to the fallout of shortage of raw materials, skilled personnel who are unable to travel for project supervisions from the affected regions, and contractors are unable to secure projects due to travel restrictions 
and self-isolations. African automotive and transportation sectors are largely affected due to shut down and closure of borders, the production of automotive parts and supply of such parts to other countries has been impacted.

\subsection{Impact on Healthcare and Pharmaceuticals}

This Pandemic is currently putting pressure on health care system in African countries though each countries are being vigilant in order to quickly diagnose and contain the viral outbreak. Early detection of the virus in African countries might be a challenge due to poor and inadequate laboratory capacity, poor technical know-how and low medical supplies. Healthcare personnel in African are not trained in relation to management and containment of Covid -19

In Pharmaceutical sector, the prices of pharmaceutical products and drugs continue to rise or unavailable because of factory closures resulting in supply chain disruptions. Some European countries refuses to export medical products and supplies like acetaminophen and other related analgesics including Antibiotics to African countries leading to shortage in Africa

\subsection{Impact on Tourism and Hospitality}

Many foreign nationals visit Africans countries as students, tourists or as business travelers, now that this virus had spread across African countries, there were restrictions on non-essential travel events are banned, tourist centers are closed and mass gatherings are prohibited, the impact on the Africa tourism sector will be high. Hotels, airlines, luxury and consumer goods have already recorded low patronage due to port closure of most African countries. Holiday visit to some Africa countries have been cancelled and people have stopped going out to entertainment centers, stadiums and kitchen cafe to avoid the risk of coming in contact with the virus. In addition, the pandemic is seriously affecting African airlines, with a significant reduction in the number of flights to other countries from Africa

How to minimize COVID-19's economic impact in Africa[21, 23, 24, 25]

The economic consequences of the outbreak may well be more significant for Africa than the epidemiological impact. With China's economic growth predicted to drop at least from 6.1 to 5.6 percent as a result of the coronavirus, African economies will also be affected. African countries thus must consider their economic responses as well as their health safeguards.

The Africa CDC has activated its Emergency Operations Center and is obtaining test kits, preparing laboratory facilities, and working with member states to support infection prevention and control and with airlines on traveler screening. Given the number of countries elsewhere reporting infections, one or more African countries will likely join their ranks

Strengthening laboratory and institutional capacity in Africa will yield dividends beyond the diagnostics for this virus, and will help African countries respond to future emerging diseases, whatever their source. Africa could become home to chains of coronavirus transmission, hence the efforts by the WHO, Africa CDC, and others to proactively respond to the current crisis. This outbreak also demonstrates, once again, the need to improve health security worldwide in line with achieving the goals of the international Global Health Security Agenda.

\section{A Baseline Framework for African Governments to Manage the Health Crisis}

Governments in African countries will need to be specific and innovative in their immediate reactions to health crisis. To effectively curtailing this Pandemic, African government needs to work together with other private organizations and other development partners.

The Authors suggest the following as a baseline framework for African governments. The framework is divided into five areas:

- Set up national response centers: Governments, with the aligned participation of the private organizations and other major stakeholders, need to create or design national response centers to coordinate and manage their immediate reactions during emergency. These centers should annex together standard leadership and administrative skills, organizational and managerial strength and digital instruments giving various leaders the best opportunities of getting ahead of events when it arises

- Earlier recognition and proper management the health crisis: Governments should adopt holistic and comprehensive approach to manage and reduce the curve of the pandemic intensifying efforts to ensure both physical and social distancing through travel restrictions, curfews and lockdowns as well as larger-scale monitoring to test cases and ensure contact tracing. In addition, African governments must be ready for a potentially upsurge in number of cases, which will require higher numbers of testing facilities, beds in isolation centers, ventilators and other medical tools and supplies, including more healthcare givers.

- Secure food supply and essential services: African governments need to properly manage food supply chains, especially food products of regular needs and ensure proper regulation and pricing of these food products for accessibility and affordability. There is also need to ensure adequate access to essential services such as telecoms, portable water supply scheme, power supply system and other basic utilities

- Adequate provision for the most vulnerable populations: This includes taking proper steps to protect workforce and provide essential services for the affected communities, particularly the most vulnerable people in the societies, through social safety and stimulus packages; including provisions of palliatives, house to house cash support and cash transfers.

- Managing the impact on the economy: Governments must quickly recognize the likely effect of this pandemic on their economy and businesses through series of analysis and offer bothlong-term and short-term stimulus 
paliatives to maintain financial stability and help businesses pull through the crisis especially the industries where their products are in high demand. Also with speculated reduction in tax revenue generation, governments will need to urgently reduce unnecessary spending.

\section{Actions for the private sector in Africa [24,26]}

The primary duty of private-sector organizations is to ensure continuity of services during anycrisis.We suggest various exigent steps for private firms; beginning with creating self-crisis control centers. These centers can manage company immediate responses on four strategic dimensions as discussed below:

- Protect workers: Ensures job protection and guarantee continuation of employment in a safe work environment and preserve the employees' health through health guidelines and safe working healthcare facilities and strict isolation of suspected cases.

- Regularize supply chains: Industries and organizations need to ensure continual conduct of business through transparent supplier engagement, demand assessment, and adjustments of production and operations.

- Engage customers: Companies need to establish crisis communication and identify the necessary changes to key market strategies and policies, ranging from guidelines and policies to sustain social distancing, waivers of cancellation and rebooking fees.

- Stress-test financials. Organizations need to create and evaluate significant impact of the crisis using epidemiological, social and economic perspectives to address and project working capital requirements. There is need to point out areas for cost reduction and containment of expenditure across the business.

\section{Actions for Development Institutions [18, 23]}

Development partners are starting to support African government in their battle against Covid- 19, for example African Development Bank (ADB) recently launched a new \$3 billion covid 19 social bond to cushion the economic and social effect of the virus; Alibaba group also support the African governments by shipping over 1 million covid-19 diagnostic tools and 100 tons of medical suppliers for control of infections to African countries through Ethiopia

In Nigeria, Coalition against Covid-19 was created by Central Bank of Nigeria in Partnership with philanthropic organization. The Coalition is mobilizing private-sector resources to support government's response to the pandemic, and increasing public sensitization and same can be said about South Africa because the largest business association in South Africa called "Business Unity South Africa", is coordinating large-scale private firms in addressing both the health and economic aspects of the pandemic

Development institutions should examine a new initiative and determine how they can support businesses and households in African countries, hence the authors suggest the following actions to be taken by the development institutions;

- Assist governments make the best decisions to address the crisis: The Institutions can provide incentives and assist governments to make good decisions in order to provide emergency response during the crisis, meet the needs of the people and ensure sustainability of healthcare and economic systems. For example, they can ensure regular supply of diagnostic materials while Government will be engaging in COVID 19 lab test

- Assist governments to plan and create business stimulus parliatives: Given the circumstances surrounding the crisis, high levels of collaborative thinking and comprehensive problem solving skills will be required to set up standard stimulus packages. Development institutions can support with valuable thought financial partnership in the countries in Africa.

- Establish new financial mechanisms to support businesses in African countries. These may include solutions like; financial bond, insurance, cash support, and more. Designing financial-support models for small and informal businesses is sacrosanct, as well as for households. This will require real creativity and true partnership between development institutions and commercial financial institutions.

- Help countries in expanding their healthcare systems. Development institutions can help supply and increase access to critical healthcare supplies by making them available and affordable, example: testing kits and masks. By increasing the capacity of the healthcare system (including the number of hospital beds); and training healthcare givers.

\section{Conclusion}

This new virus outbreak has challenged the economic, medical and public health infrastructure of African countries. Future upsurge of viruses and pathogens of zoonotic origin are likely to continue. Therefore, apart from curbing this outbreak, efforts should be made to devise comprehensive measures to prevent future outbreaks of zoonotic history. In the absence of comprehensive and holistic approach, the health consequences, economic impact and spread of this virus in poorer nations may linger for a long time.

It is necessary to consider updating the case definition for surveillance, however, more detailed studies presenting evidence on the epidemiological nature, more clinical presentations, and pathogenesis of 2019-nCoV are necessary to provide adequate information for public health decision-makers. Laboratory and institutional capacity in African Countries must be strengthened so that they can develop and conduct new drug and vaccine trials independently in an emergency situation 


\section{References}

i. WHO Emergency Committee Statement on the second meeting of the International Health Regulations (2005) Emergency Committee regarding the outbreak of novel corona virus (COVID-19). WHO, Geneva 2020 https://www.who.int/news-room/detail/30-01-2020-statement-on-the-second-meeting-of-the-internationalhealth-regulations-(2005)-emergency-committee-regarding-the-outbreak-of-novel-coronavirus-(COVID-19). Date accessed: April 1, 2020

ii. WHO Novel coronavirus (COVID-19) situation report-22. Https://www.who.int/docs/defaultsource/coronaviruse/situation-reports/20200211-sitrep-22-ncov.pdf?Sfvrsn=fb6d49b1_2 Date: $2020 . \quad$ Date Accessed: April 3, 2020

iii. WHO Regional Office for Africa WHO ramps up preparedness for novel coronavirus in the African region. Https://www.afro.who.int/news/who-ramps-preparedness-novel-coronavirus-african-region Date: 2020. Date accessed: April 3, 2020

iv. Xinhua. China's CDC detects a large number of new coronaviruses in the South China seafood market in Wuhan. Available at: https://www.xinhuanet.com/2020-01/27/c_1125504355.htm. Accessed 20 Feb 2020.

v. Huang C, Wang Y, Li X, et al. Clinical features of patients infected with 2019 novel coronavirus in Wuhan, China. Lancet. 2020; 395: 497-506.

vi. Chen N, Zhou M, Dong X, et al. Epidemiological and clinical characteristics of 99 cases of 2019 novel coronavirus pneumonia in Wuhan, China: a descriptive study. Lancet. 2020; 395:507-13.

vii. WHO. Clinical management of severe acute respiratory infection when novel coronavirus [ncov] infection is suspected. Available at: https://www.who.int/publications-detail/clinical-management-of-severe-acuterespiratory-infection-when-novelcoronavirus-[ncov]-infection-is-suspected. Accessed 9 Feb 2020.

viii. Huang P, Liu T, Huang L, et al. Use of chest CT in combination with negative RT-PCR assay for the 2019 novel coronavirus but high clinical suspicion. Radiology. 2020. Https://doi.org/10.1148/radiol.2020200330.

ix. Zhang L, Liu Y. Potential interventions for novel coronavirus in China: a systemic review. J Med Virol. 2020. Https://doi.org/10.1002/jmv.25707.

x. Chang D, Xu H, Rebaza A, Sharma L, Dela Cruz CS. Protecting health-care workers from subclinical coronavirus infection. Lancet Respir Med. 2020. Https://doi.org/10.1016/S2213-2600(20)30066-7.

xi. Lei J, Kusov Y, Hilgenfeld R. Nsp3 of coronaviruses: Structures and functions of a large multi-domain protein. Antiviral Res. 2018 Jan; 149:58-74.

xii. Coronavirus Outbreak. Available at: https://www.worldometers.info/coronavirus/. Accessed 23 Feb 2020.

xiii. Middle East Respiratory Syndrome Coronavirus. Available at: https://www.who.int/emergencies/mers-cov/en/. Accessed 16 Feb 2020.

xiv. Jin YH, Cai L, Cheng ZS, et al. A rapid advice guideline for the diagnosis and treatment of 2019 novel coronavirus [2019-ncov] infected pneumonia. Mil Med Res. 2020; 7:4.

xv. Chen Z-M, Fu J-F, Shu Q et al. Diagnosis and treatment recommendations for pediatric respiratory infection caused by the 2019 novel coronavirus. World J Pediatr. 2020:1-7. Https://doi.org/10.1007/s12519-020-00345-5.

xvi. World Health Organization. Coronavirus disease [COVID-19] Technical Guidance: Infection Prevention and Control. Available at: https://www.who.int/emergencies/diseases/novel-coronavirus-2019/technicalguidance/infection-prevention-and-control. Accessed 20 Feb 2020.

xvii. David E., Mead O. (2020) The Economic Impact of COVID-19 in Low- and Middle-Income Countries .Commentary and Analysis. Center for Global Development

xviii. Kartik I., Acha L. (2020) Tackling COVID 19 in Africa. Commentary. Mckinsey \& Company

xix. Africa Center for Disease Control and Prevention. Coronavirus - Africa: COVID-19 Surveillance Update -Afrcanews by Abdur Rahman Shaban Date: April 7th, 2020

xx. World Health Organization data base Coronavirus disease 2019 (COVID-19) Situation Report - 51 Data as reported by national authorities. March 2020

xxi. Baker mckenzie and Company; Impact of COVID 19 on key African Sectors, March 2020, Coronavirus Resource Center

xxii. Tanu Singhal: (13 March 2020). A Review of Coronavirus Disease-2019 (COVID-19). The Indian Journal of Pediatricsvolume 87, pages281-286

xxiii. Africa Center for Strategic Studies, “Lessons from the Joint Force Command's Response to the Ebola Crisis," Spotlight, December 5, 2014.

xxiv. Xiaobo Zhang COVID-19's Impact on China's Small and Medium-sized Businesses Independent Research for global Prosperity; Commentary and Analysis .Date accessed: March 17, 2020

xxv. Center for strategic and International studies: COVID-19 Is an African Political Crisis as Much as a Health and Economic Emergency. March 18, 2020.

xxvi. Mckinsey and Company; COVID-19: Implications for business. March 2020 | Executive Briefing 